\title{
Peculiarities, values and Youth Social Orientation in the Rural Territories in the Republic of Bashkortostan, in Modern Economic Conditions
}

\author{
Eugene Stovba \\ Birsk branch of Bashkir State \\ University \\ 452450, International, 10, Birsk, \\ Russia \\ stovba2005@rambler.ru
}

\author{
Andrey Stovba \\ Birsk branch of Bashkir State \\ University \\ 452450, International, 10, Birsk, \\ Russia \\ stovbaav2006@rambler.ru
}

\author{
Natalya Kolonskikh \\ Birsk branch of Bashkir State \\ University \\ 452450, International, 10, Birsk, \\ Russia \\ dangerous454@mail.ru
}

\begin{abstract}
The article states the necessity of studying the youth value and social orientations in rural regions in the Russian Federation. The rural youth is seen as an accurate indicator of social problems in public life. It is proposed to use various methods to study the problem of the rural youth value and social orientations. Methodical approaches to solving social and economic problems of youth in rural areas are specified. According to the results of sociological monitoring, the youth values and social orientations in the rural areas are singled out.
\end{abstract}

Keywords - rural youth, value and social orientations, rural areas, rural economy

\section{INTRODUCTION}

At present, the important and urgent task of domestic research is studying of youth value orientations and social problems, the specificity of the spiritual, cultural, psychological, moral and spiritual condition in rural areas of the Russian Federation. The modern development of rural areas in this country's regions determines the objective necessity to apply a systematic approach for assessing the creative potential and morale of young villagers, their commitment to the conservative way of rural life and traditional folk culture - all these demonstrates the progressive and dominant tendencies to maintain stability in society.

Certainly, the consequences of economic reforms carried out by the Russian government are especially pronounced in the development of rural youth value and social orientations, including those reflected in their behavior [1, 2]. One can agree with the assertion that «matters of value orientations in the youth part of the society in the context of the dynamics of socio-economic processes are of current interest due to the lack of theoretical elaboration and practical significance of the topic» [3, p. 15].

Of course, the study of young people values and social orientations, the relevance of their comprehension and the development of constructive solutions are determined not only by the current tasks of ongoing scientific research, but also by the development and future of the state and the individual, the country and the whole of Russian society [4, 5]. A.V.
Gavrikova rightly notes, "The study of young people value orientations implies an assessment in the structure and dynamics of value priorities and the key factors identification that affect the individual's social well-being and value consciousness. The identification of value orientations is necessary for understanding in which spheres of life the object prefers to concentrate his efforts» $[6, \mathrm{p} .19]$. At the same time, as R.M. Sadykov states, the rural youth is the most socially disadvantaged part of modern Russian society and it has a number of features that stem primarily from its very entity, which are determined by the territory of residence and socio-economic status [7, p. 15].

Values and social orientations of rural youth can constantly vary depending on changes in their lifestyle and behavior. At the same time, the creation of certain value orientations, the setting of their life credo allows young people to find their place in the modern society. V.M. Kuzmina correctly writes that «the definition of the life path of rural youth is, in turn, the choice of socio-professional status and socio-territorial movements in order to realize life plans») [8, p. 24]. The lack of a clearly formulated life position in a significant part of young people forms its social disorientation in a market economy and reflects its lack of understanding its status and role in modern society.

\section{RESULTS AND DISCUSSION}

In 2016-2017, we conducted research on the identification of value and social orientations among young people living in rural municipalities in the Republic Bashkortostan. In carrying out the sociological research, the fact that the existing sociodemographic structure of rural residents in the republic is determined by specific value, moral and cultural conditions of life was considered, and the rural population is characterized by certain social and environmental conditions in their work. The features of the place residence (a particular rural area), as well as the specific youth characteristics of the people interviewed, make it possible to allocate youth from the total mass of the rural population of the region.

In the process of implementing the monitoring, such mental and psychophysiological features of rural youth as 
dynamism, mobility, adaptability, efficiency, studying and optimism were considered. When forming the results of the study, probable variations of the answers from the specific formulation of questions; attitudes and stereotypes that were formed in the representatives of rural youth, taking into account the views of parents, relatives and friends; possible concealment by young people of their position were taken into account.

There is a special naivety and sincerity in answering the questions posed for young people, they have life attitudes that are based on straightforwardness in their opinion and traditionalism. At the same time, it is typical for rural girls and young men to keep quiet about their problems; they may hesitate to truthfully distinguish their true interests and desires, intentions and motives in their answers. It was taken into account that representatives of rural youth, as a rule, spend significantly less time improving their qualifications, compared with their senior colleagues; young people quickly master their related work specialties in the team, than their peers.

During the interviews, all the respondents were divided into two groups, namely: pupils of rural high schools aged from 14 to 17 and young people - workers of agricultural structures aged 18 to 27 years. Also, young workers engaged in agricultural labor were grouped according to family relations (married or single), by gender (women or men), by the profile of work (agricultural organizations, personal subsidiary or farmer households).

According to the results of the monitoring, the majority of the interviewed expressed as their socially-targeted position"To be financially secured". The target and dominant life strategy of the students is determined by the motive «it is necessary to achieve success in life» $(77 \%$ of interviewed respondents). Young people consider themselves as the "generation of hopes» (39\% of respondents), «aggressive generation» $(13 \%$ of respondents), «pragmatic generation» and «deceived generation» ( $8 \%$ of respondents). The opinion of a small part of university students - those who come from rural areas mainly reflects the «cynical generation» $(15 \%$ of respondents).

It is possible to note the predominance of the positive attitude among the most significant part of the respondents, who are related to the «generation of hopes». At the same time, it is necessary to point out the popularity of such an answer as «aggressive and cynical generation which is undoubtedly associated with a significant decrease in the quality in recent decades of the population life in most rural municipalities in the Republic Bashkortostan.

In the system of values formed, young people are more focused on the opportunities for harmonious communication, social guarantees, the prestige of work, favorable social conditions of work. However, it is not easy for employers to encourage young people to significantly increase their labor productivity, and they have to use different tools of motivation, in particular, intangible motivation.

The survey results reflect the lack of interest among many representatives of rural youth in organization of their farming, the development of small businesses in rural areas. Such a negative reaction of respondents who participated in the study is largely due to the negative conditions in the agricultural labor organization, which has developed in the countryside. The negative opinion of young people about the formed agricultural way of life and rural life is expressed in inadequate perception of the rural society behavior and underreporting of the moral assessments of the villagers, lack of satisfaction in the social and cultural needs of young people, lack of normal conditions for employment in rural areas or, conversely, the formation of rural over-employment.

As a result, all this determines the decrease in the share of responsibility in a certain part of youth for their behavior and shows a kind of moral alienation among young people from the actual established social attitudes formed in the rural environment. This circumstance was taken into account during the present study and made it possible to determine the specific features of the values and social orientations of youth in the rural areas of the region (Table 1).

TABLE 1. THE RESULTS OF SOCIOLOGICAL SURVEYS TO DETERMINE THE VALUE AND SOCIAL ORIENTATIONS OF THE YOUTH IN RURAL AREAS OF THE REPUBLIC BASHKORTOSTAN, \%

\begin{tabular}{|l|c|c|c|c|c|}
\hline & \multicolumn{5}{|c|}{ Values and social orientations } \\
\cline { 2 - 6 } Groupings & $\begin{array}{c}\text { Good } \\
\text { relations } \\
\text { in the } \\
\text { family }\end{array}$ & $\begin{array}{c}\text { Interesting } \\
\text { work, it's } \\
\text { about liking }\end{array}$ & $\begin{array}{c}\text { Attitude } \\
\text { to religion }\end{array}$ & $\begin{array}{c}\text { Interesting } \\
\text { and loyal } \\
\text { friends }\end{array}$ & $\begin{array}{c}\text { Material } \\
\text { well-being, } \\
\text { high } \\
\text { incomes }\end{array}$ \\
\hline $\begin{array}{l}\text { Group by } \\
\text { sex: } \\
\text { - young men } \\
\text { - girls }\end{array}$ & 15.5 & 18.3 & 8.6 & 12.4 & 20.5 \\
\hline $\begin{array}{l}\text { Grouping by } \\
\text { status } \\
\text { training: } \\
\text { - students } \\
\text { - students }\end{array}$ & 15.0 & 20.1 & 7.5 & 11.1 & 18.5 \\
\hline $\begin{array}{l}\text { Grouping } \\
\text { across the } \\
\text { entire } \\
\text { sample }\end{array}$ & 14.0 & 16.6 & 8.5 & 12.2 & 19.0 \\
\hline
\end{tabular}

The table data show that for interviewed young villagers the priorities are material well-being, prosperity and high wages, the possibility of obtaining interesting work. The social orientations of rural youth also reflect a happy relationship with friends and in the family. The data obtained are consistent with the research of Russian and Ukrainian scientists who note that rural youth consider family, friends, health and work, material well-being, leisure as the main vital values, which in turn testifies to the urgency and aggravation of youth problems in these spheres [9, p. 12]. At the same time, about $8.5 \%$ of the young people surveyed formed their attitude towards religion, including $8.5 \%$ of school students and $7.4 \%$ of students. At the same time, the responses of students of rural youth and students largely correlate; however, the gender specificity of the answers of students who come from rural areas is more differentiated.

The most important indicator, reflecting the state's interest in the development of the economy and social sphere, is the level of wages. The conducted research allows to speak about the critical attitude of young people in relation to wages in the agricultural sector and to work in rural areas. The representatives of young people believe that many rural residents, in contrast to the urban population of the republic, live below the poverty line and «drag out existence» $(71 \%$ of 
the respondents' answers). The significant part of the respondents believe that the level of workers incomes employed in agriculture is untenable in the region (as well as in the national average).We can agree with the statement «the material factor is of great importance for modern youth. That is, in the minds of young people, the financial situation determines success, prosperity and stability» [10, p. 115]. About $75 \%$ of the young people surveyed believe that the main factors hampering the economic development of the agrarian sector in the region are the disparity of prices for industrial and agricultural goods; the sanctions of the USA and its allied countries imposed on this country; low purchase prices for goods produced by domestic agro-formations. The young people single out such economic problems in the countryside as high taxes, imperfect legislation, lack of real assistance from the administration of rural municipal districts. At the same time, $59 \%$ of respondents are optimistic about the fact that, it is possible to work in agribusiness without breaking legislation. According to the majority of rural youth representatives, corruption is the main obstacle to the development of agribusiness in the countryside, as well as a lack of practical experience in agricultural production.

Separately for the young people - workers of agricultural organizations and pupils of the senior classes of rural schools, we compiled the questionnaires «The Young Farmer», "The Rural Youth» and «The Learning Youth» with eleven variants of value, social attitudes on two criteria of significance. So, in the formed questionnaire «The Young Farmer» the following questions were presented:

1. What is the size of your farm?

2. What is the motivation for starting your farm?

3. What organizational problems did you have when starting your own farm?

3. What profit does your farm bring to you?

5. Do you think is it possible to deal with agribusiness successfully and do not break the law?

The results of processing the answers to the above questions lead to the conclusion that the rural youth representatives have a slightly different position compared to the opinion of older age groups of the population in rural areas of the region. Thus, about the half of the rural youth surveyed believe that farms should receive support for development and a much smaller number of young people, in comparison with the older population, believe that the only form of farming in agriculture should be state farms and collective farms. A significant number of young people are in favor of mixed and mixed agriculture and believe that different agro formations of all forms of ownership must be represented in the village.

The difference in the formed positions can be explained in such a way, that young villagers have more mobile and clearly expressed psyche. The rural youth, in comparison with the older generation, is mainly open to the introduction of various innovations and new values of life, which correspond to modern economic realities.

Thus, young people are mostly neutral about the implementation of modernization reforms in the countryside, but objectively allocate the social costs that arise in this case. This causes for some part of rural youth a decrease in the sense of responsibility for their behavior towards the external environment, determines moral alienation and forms a certain disdain for creative labor activity.

It is necessary to allocate such highly educated and active category of studying youth, as students and post-graduate students, participating in the survey. Among this group, there are more pessimists, since they, as people from the village, are well aware of the real state of affairs in agriculture. About $25 \%$ of the students, surveyed and graduate students believe that in the short term the situation in rural areas will improve.

Over $70 \%$ of respondents are worried about poor working conditions and lack of modern technologies in rural areas, lack of prospects for career growth. In this case, this group is more demanding for housing improvement and development of social infrastructure in the countryside, as every third interrogated person is married. At the same time, about $30 \%$ of respondents from among young farmers and rural specialists who have recently graduated or are studying at the correspondence department of universities agreed to stay in rural areas. Of course, the social motives of young people employed in agriculture differ from the motivation of employees who are not related to this profile of production activities.

The motivation for obtaining higher education varies under the influence of the actual state of the society itself, the position it has formed for the prestige of work and the relevance of different professions and depends on such characteristics as social status, material security, and level of culture and the education of a young person. Absolute majority of rural young people consider higher education as a certain standard of living for migration to small and large cities of the republic. According to A.A. Bogatkina: «The most significant influence on the changes occurred was the value orientations and life strategies of the younger generation in the field of professional socialization. Thus, the receipt of a certain education becomes an integral part of the process of acquiring a sustainable level of wages and a stable social position in society» $[11$, p. 54$]$.

Among the student youth, people from the villages, there is a combination of pessimism (about the future employment in the specialty received in higher education institutions) and optimism (about their personal economic and social development prospects). It can be stated, that today young people are characterized as dependent and they have the gradual change of the priorities moral development. For a certain category of young people, it is common to live only today and nouveau is prevalent. One can agree with the opinion of M.R. Yuldasheva, who notes: «The breakdown of value orientations is reflected in the mood of the youth. It is the growing disappointment in the prospects, which leads to the spread of nihilism, the reduction of moral criteria among young people» [12, p. 49].

The goal of any person is to become self-fulfilling, to become successful and to be accepted in the surrounding society, however, in the presence of high competition in economically efficient sectors and activities and the existing low professional culture, the representatives of rural youth receive a rich negative experience that forms their negative self-esteem. In the future, this acquired low self-esteem can significantly affect the outlook and future work of young people from rural areas. 
The actual situation of the rural territories in the Republic of Bashkortostan negatively affects the development of the teenage and children's rural environment through:

- the increase in the number of orphans;

- the reduction of workers incomes engaged in agriculture;

- the reducing the availability of social, educational, medical and cultural services for rural residents;

- the growth of poverty and strengthening of property differentiation in rural areas;

- the reduction in the budget in rural municipal districts of the share of expenditures for medical, domestic and sociocultural services for residents.

It should be noted that the most important social problems of young people are housing security, employment, the adaptation to the present conditions of life in rural areas. The rural youth, first of all, is concerned with the rational functioning of the social infrastructure, the prospects for the functioning of medical services and education in rural areas. The instability in the development of agriculture directly affected the functioning of the social sphere, which, in turn, led to aggravation of social problems in the rural areas in the region (Table 2).

TABLE 2. INDICATORS OF DEVELOPMENT IN THE SOCIAL SPHERE AT RURAL TERRITORIES IN THE REPUBLIC OF BASHKORTOSTAN IN 2010-2016 [13, 14]

\begin{tabular}{|l|c|c|c|c|}
\hline \multicolumn{1}{|c|}{ Indicators } & \multicolumn{4}{|c|}{ Years } \\
\cline { 2 - 5 } & $\mathbf{2 0 0 5}$ & $\mathbf{2 0 1 0}$ & $\mathbf{2 0 1 5}$ & $\mathbf{2 0 1 6}$ \\
\hline $\begin{array}{l}\text { The number of pre-school educational } \\
\text { organizations, units }\end{array}$ & 1300 & 1165 & 723 & 619 \\
\hline $\begin{array}{l}\text { The number of state and municipal } \\
\text { daytime } \\
\text { general educational } \\
\text { organizations, units. }\end{array}$ & 2680 & 1408 & 982 & 966 \\
\hline $\begin{array}{l}\text { The number of emergency medical } \\
\text { stations help, unit. }\end{array}$ & 38 & 40 & 37 & 37 \\
\hline $\begin{array}{l}\text { The number of medical hospital beds, } \\
\text { thousand units. }\end{array}$ & 8.6 & 5.9 & 5.3 & 5.2 \\
\hline The number of public libraries, units & 1569 & 1510 & 1438 & 1410 \\
\hline $\begin{array}{l}\text { The number of institutions of cultural- } \\
\text { leisure type, units }\end{array}$ & 2419 & 2287 & 2047 & 2014 \\
\hline
\end{tabular}

While forming the value orientations of rural youth, it is important to educate the right moral way of life and the level of cultural provision. It is necessary to state that in 2005-2016 the number of pre-school institutions in rural areas in the Republic of Bashkortostan decreased by 681 units in 2.1 times. The number of rural schools in the comparative period as a whole in the region decreased by 1714 units in 2.8 times. Such a significant decrease in the number of small schools in rural areas is associated with inadequate funding and a significant deficit in the budgets of most rural municipalities in the region. In addition, the technical equipment and computerization of urban schools, as a rule, is much higher than in rural schools, which causes unequal opportunities for young people to get high-quality educational services from the village.

In recent years, the level of cultural services in rural areas has significantly decreased, which is primarily due to a decrease in the number of rural clubs and libraries. Similar trends are taking place in the sphere of medical provision and servicing of rural residents, with an active reduction in the number of rural health care institutions and medical stations.
In rural areas of the republic, there are not enough sports and health facilities, so a small percentage of rural young people study physical culture and sports.

The growth of social problems in the country causes the popularity of answers related to feelings of «deceit, aggressiveness and cynicism» among representatives of young people living in rural areas and causes the development of social tension and the emergence of social problems in the rural environment. At the same time, it is necessary to note a pronounced correlation between the increase in the age of the interviewed young people and the increase in the indices of «anxiety».

In fact, the current situation, related to the problems of the future employment of graduate students, determines the social well-being of young people. The low level of demand for those young people who do not have practical experience of labor activity and vocational training causes a high level of unemployment in the rural labor market. At the same time, according to monitoring results, $52 \%$ of respondents recognize that they can work in rural areas if a comfortable social environment is created for them, similar to urban conditions, which ensures a high quality of life.

Another key problem that prevents the attraction of the former students to the countryside is the inadequate level of provision of their own homes for future teachers and doctors. Insignificant volumes of mortgage lending and housing construction in rural areas do not allow to satisfy the potential demand of young people for housing.

The problem of housing provision for young villagers, in turn, prevents the attraction and consolidation of young graduates to the institutions of the budgetary sphere of rural areas. Young people have relatively high requirements for many aspects of socio-labor activity in the countryside, and, especially, to the leisure and everyday life. A survey of rural youth from the northern municipal formations showed that a certain proportion of the respondents is not satisfied with the existing living conditions in the countryside (Table 3).

TABLE 3. THE RURAL YOUTH ATTITUDE TO THE LIFE CONDITIONS IN THE NORTHERN MUNICIPAL FORMATIONS IN THE REPUBLIC OF BASHKORTOSTAN, $\%$

\begin{tabular}{|l|c|c|}
\hline \multicolumn{1}{|c|}{ Rural Municipalities } & Negative & Positive \\
\hline Arkhangel'skiy & 31 & 34 \\
\hline Askinsky & 33 & 40 \\
\hline Baltachevsky & 42 & 37 \\
\hline Birsky & 32 & 51 \\
\hline Blagoveschensky & 30 & 42 \\
\hline Buraevsky & 35 & 38 \\
\hline Kaltasinsky & 31 & 27 \\
\hline Karaidelsky & 37 & 39 \\
\hline Krasnokamsky & 36 & 38 \\
\hline Mishkinsky & 31 & 46 \\
\hline Nurimanovsky & 34 & 27 \\
\hline Tatyshlinsky & 24 & 50 \\
\hline Chekmagushevsky & 32 & 41 \\
\hline Yanaulsky & 42 & 28 \\
\hline
\end{tabular}

Undoubtedly, the crisis phenomena in rural areas have a negative impact on the formation of value orientations and social perception of reality for rural youth. Behavioral factors are directly related to the motivation for surviving in the 
cardinally changing living conditions and adaptation of young people to the countryside.

\section{CONCLUSION}

The historical experience of scientific research shows that a rapidly developing society relies, mainly, on the young generation. Of course, young people are not always progressive and conservative, they, above all, represent a certain force that is ready for any undertakings and cardinal reforms.

The rural youth can be considered as a common value group of young people, which reflects the level of development of the entire young generation of the Russian Federation with all its problems and characteristic features. At the same time, it, represents the whole dynamic society, present and future, has a pronounced social status and is a kind of children-youth substratum of all rural inhabitants in the region.

It is important to emphasize that the problem of positive value formation and social attitudes for rural youth can be solved only with the successful implementation of economic reforms in the village with taking into account the growth of motivation and increasing the attractiveness of agricultural labor. The rural youth, as a certain social group of the population, is a hidden demographic resource for the development of rural territories and a strategic reserve for the reproduction of labor in agro-formations.

In our opinion, it is necessary to adopt a set of practical measures for development today, such as the social and professional orientation of rural youth, training, retraining, consolidation and improvement of skills of young qualified personnel in rural areas in the Republic of Bashkortostan. The main targets for young people - people from the village in terms of motivation employment in rural areas should be:

- the preservation and retention of highly qualified personnel;

- the attraction of highly qualified specialists;

- the development of the desire for employees and managers at enterprises and organizations to pursue career growth and to increase their professional knowledge;

- the stabilization of the labor force in budgetary organizations and minimization of the turnover level of personnel potential at these institutions.

Therefore, the conducted research helps to distinguish the real value and social orientations youth in rural areas in the region at the current economic conditions. The value and socialization are directly related to the potential, the motivation for survival of every person in rural areas, and, above all, with the adaptation of the growing generation to phenomenally changing conditions. Ensuring a high level and quality of life for young people in rural areas and creating a comfortable social environment will certainly contribute to sustainable development of rural areas in the Republic of Bashkortostan and other subjects of the Russian Federation.

\section{REFERENCES}

[1] Gabidullina G.R., Yagudina A.R., Vasiliev A.Yu. Trends in changing value orientations of rural youth in modern socio-economic conditions // Scientific review. - 2016. - No. 19. - P. 272-277.

[2] Shinkovskaya N.V., Golyankin E.O. The problem of professional orientation of young people in the context ofeconomic and social transformations in modern Russia // Interactive science. - 2016. - No. 1. - P. 82-85.

[3] Bagieva M.G., Kulova M.R., Fedosova E.V. Socio-economic aspects of youth value orientations in the Republic of North Ossetia - Alania // Society: sociology, psychology, pedagogy. - 2017. - No. 11. - P. 15-20.

[4] Bykova N.L. Orientation to status as the resultant social situation of youth developmentperiod at the beginning of the world economic crisis // Bulletin of the Samara Humanitarian Academy. Series:Psychology. 2010. - No. 1. - P. 39-49.

[5] Savchina M.D. The influence of value orientations on the ethnic tolerance of urban and rural youth of at years // Scientific discussion: questions of pedagogics and psychology. - 2015. - No. 12-2 (45). - P. 125-136.

[6] Gavrikova A.V. Value orientations of young people in the global economic crisis: the factors of formation and features of transformation // Advances in modern science. - 2016. - T. 9. - No. 11. - P. 19-22.

[7] Sadykov R.M. Professional preferences and value orientations of rural youth //Advances in modern science. - 2016. - T. 9. - No. 11. - P. 15-18.

[8] Kuzmina V.M. Comparative analysis of value orientations of rural and urban studentyouth, studying at the Kursk State Agricultural Academy // Society: sociology,psychology, pedagogy. - 2012. - № 3. - P. 22-28.

[9] Chigrin V.A., Chigrina N.V. The role and place of value orientations in the system of lifeself-determination of rural youth // Actual problems of socio-humanitarian and scientific-technical knowledge. - 2014. - No. 2 (3). - P. 12-15.

[10] Sugutina A.A., Fedorova K.A., Demtsura S.S. Economic behavior and features of the economic value orientations of youth // Integration of sciences. - 2017. - No. 6 (10). - P. 113-116.

[11] Bogatkina A.A. The economic paradigm of modern education and its impact on valueorientation of youth // Izvestiya of the St. Petersburg University of Economics and Finance. - 2011. - No. 5. - P. 53-56.

[12] Yuldasheva M.R. The value orientation of modern youth as an aspect of self-regulation of economic behavior // A new word in science and practice: hypotheses and approbation of research results. - 2013. - No. 3. - P. 48-52.

[13] Agriculture, hunting and forestry of the Republic of Bashkortostan: a statistical compilation. - Ufa: Bashkortostan stat, 2017. - 202 p.

[14] Social and economic situation of municipal districts and urban districts of the RepublicBashkortostan: a statistical collection. - Ufa: Bashkortostan stat, 2017. - 281 p. 